\title{
Correction to: Influence of In Vitro Electrical Stimulation on Survival of Spiral Ganglion Neurons
}

\author{
Marvin N. Peter ${ }^{1}$ (10 $\cdot$ Athanasia Warnecke ${ }^{1,2} \cdot$ Uta Reich $^{3} \cdot$ Heidi Olze $^{3} \cdot$ Agnieszka J. Szczepek $^{3} \cdot$ Thomas Lenarz $^{1,2}$. \\ Gerrit Paasche ${ }^{1,2}$
}

Published online: 4 April 2019

(C) Springer Science+Business Media, LLC, part of Springer Nature 2019

Correction to: Neurotoxicity Research (2019) 34:525-537

https://doi.org/10.1007/s12640-019-00017-x

The first multiplication sign (.) for unit $\mu \mathrm{C} \mathrm{cm}^{-2}$.phase ${ }^{-1}$ was not placed, which is part of the author's correction. Furthermore, the unit appears anywhere in the article.

The original version has been corrected.

Publisher's Note Springer Nature remains neutral with regard to jurisdictional claims in published maps and institutional affiliations.

The online version of the original article can be found at https://doi.org/ 10.1007/s12640-019-00017-x

Athanasia Warnecke

Warnecke.Athanasia@mh-hannover.de

1 Department of Otorhinolaryngology, Head and Neck Surgery Hannover Medical School, Stadtfelddamm 34,

30625 Hannover, Germany

2 Cluster of Excellence "Hearing4all" of the German Research Foundation, Oldenburg, Germany

3 Department of Otorhinolaryngology, Head and Neck Surgery, Berlin Institute of Health, Charité - Universitätsmedizin Berlin, Corporate Member of Freie Universität Berlin, Humboldt-Universität zu Berlin, Berlin, Germany 